\title{
The effects of nematode parasitism on the rate of passage of food residues through the alimentary tract of sheep
}

\author{
By R. J. BAWDEN* \\ Department of Parasitology, University of Queensland, St Lucia, \\ Brisbane, Queensland, Australia
}

(Received 2 fuly 1969-Accepted 22 fuly 1969)

\begin{abstract}
r. The mean retention time of stained food residues was longer in sheep maintained on a chopped straw ration than in sheep maintained on a chopped lucerne ration.

2. Infection of sheep with I500 infective Oesophagostomum columbianum juveniles was associated with increased mean retention times.

3. The extent to which the mean retention times were increased was associated with the diet and mode of infection of the sheep.

4. It was noted that an increase in mean retention time following infection was associated with a general decrease in food intake per $\mathrm{kg}$ live weight ${ }^{0.75}$.

5. The results are discussed in relation to the pathogenesis and survival of $O$. columbianum infections in sheep.
\end{abstract}

Infection of young sheep with the parasitic nematode Oesophagostomum columbianum, especially those maintained on a low plane of nutrition, results not only in anorexia but also in decreased efficiency of utilization of ingested nutrients (Bawden, 1969a). Blaxter, Graham \& Wainman (1956) noted that the efficiency of utilization of nutrients was influenced in ruminants by the rate of flow of ingesta through the alimentary tract and that this was directly correlated with the amount of feed consumed.

An association between the rate of flow of ingesta and the extent of establishment and survival of parasitic helminths in the intestines of animals has been recorded (Larsh, 1947, 1950; Larsh \& Hendricks, 1949).

The investigation described below was carried out to examine the interrelationships between the nutritional status of sheep and nematode parasitism with respect to the rate of flow of food residues through the alimentary tract.

\section{EXPERIMENTAL}

The experiments were carried out with Merino $\times$ Border Leicester lambs maintained on different dietary regimes, following random allocation, and infected with $O$. columbianum. Seven ram lambs reared free from helminths were used. Three lambs were maintained on a ration consisting exclusively of lucerne chaff (the high plane-HP group), and the other four on a mixture of wheaten straw and molasses (the low plane-LP group). Both rations were available ad lib. An analysis of the major constituents was assessed according to methods of the Association of Official Agricultural Chemists (1960). The gross energy was measured in a Gallenkamp adiabatic bomb calorimeter. The results of these analyses are shown in Table I.

* Present address: Department of Agricultural Biology, University of New England, Armidale. N.S.W. 2351, Australia. 
Table 1. Composition of experimental diets

\begin{tabular}{|c|c|c|c|c|c|c|c|c|}
\hline \multirow[b]{2}{*}{ Diet } & \multirow[b]{2}{*}{$\begin{array}{c}\text { Main } \\
\text { constituent }\end{array}$} & \multirow[b]{2}{*}{$\begin{array}{c}\text { Molasses } \\
(\%)\end{array}$} & \multirow[b]{2}{*}{$\begin{array}{c}\text { Dry } \\
\text { matter } \\
(\%)\end{array}$} & \multicolumn{5}{|c|}{ Composition of dry matter } \\
\hline & & & & $\begin{array}{l}\text { Total } \\
\text { protein } \\
(\%)\end{array}$ & $\begin{array}{l}\text { Crude } \\
\text { fibre } \\
(\%)\end{array}$ & $\begin{array}{c}\text { Ether } \\
\text { extract } \\
(\%)\end{array}$ & $\begin{array}{l}\text { Ash } \\
(\%)\end{array}$ & $\begin{array}{l}\text { Energy } \\
(\mathrm{kcal} / \mathrm{g})\end{array}$ \\
\hline $\mathrm{HP}$ & $\begin{array}{l}\text { Chaffed } \\
\text { lucerne }\end{array}$ & - & $85 \cdot I$ & 19.4 & $29^{\prime} 3$ & $2 \cdot 68$ & 8.9 & $4 \cdot 28$ \\
\hline LP & $\begin{array}{l}\text { Chaffed } \\
\text { wheaten } \\
\text { straw }\end{array}$ & I 5 & $81 \cdot 8$ & $6 \cdot 8$ & $38 \cdot 5$ & $2 \cdot 01$ & $6 \cdot 6$ & $4 \cdot 01$ \\
\hline
\end{tabular}

\section{Measurement of retention time}

This measurement was based on the method of Balch (1950), who used a small portion of stained roughage as a marker and noted its subsequent excretion in the faeces. Samples of the two diets were stained with a $0.025 \%$ solution of basic fuschin according to the method of Castle (1956).

Approximately $10 \mathrm{~g}$ of the respective stained diets were offered to the animals immediately before feeding. Feed intake and faecal output were measured hourly and samples of the faeces were examined for the presence of stained particles. Once these were evident, sampling was continued at $4 \mathrm{~h}$ intervals for the first 3 days, followed by $6 \mathrm{~h}$ intervals for the following 2 days and thereafter at $12 \mathrm{~h}$ intervals until the number of stained particles observed in the faeces was very small, when samples were collected at $2 \mathrm{~h}$ intervals until no further marker appeared.

Counting of faecal particles. Each collection of faeces was weighed and, after thorough mixing, four samples totalling approximately $40 \mathrm{~g}$ were taken. These were homogenized and a smear from the homogenate was placed on each of four squares of paper towelling which had previously been weighed after drying at $105^{\circ}$ for 24 h. These paper squares were stretched over an embroidery frame. A grid made of fine cotton strands stretched over another frame and arranged in square centimetres was then placed over the sample which was examined by reflected light under a $\times 12$ magnification. The number of particles present in the smear was counted, after which each paper was re-dried at $105^{\circ}$ for $24 \mathrm{~h}$ and re-weighed. The particle count was expressed as the mean of the number of particles recorded in the four samples per $g$ dry faeces. The total dry weight of the faeces excreted during each collection period was calculated and the particle count was converted to the total number of particles passed in the faeces during each period.

The particle counts were plotted as cumulative curves from which were calculated the respective values for mean retention time by the method of summing at $10 \%$ intervals, the excretion times between 5 and $95 \%$, and dividing by 10 , as proposed by Castle (1956).

Statistical analysis of the results was achieved by the use of Student's $t$ test. The small number of degrees of freedom available for analysis between any two treatments was deemed undesirable and thus all the variances involved were pooled after examination of their homogeneity by the use of Bartlett's test. 


\section{Infection}

The rate of passage before infection was measured in three LP and three HP animals. The sheep were $3 \circ$ weeks old at the start of the experiment and had been maintained on their respective rations for 8 weeks.

The second set of observations was collected from the same three LP animals plus an extra one which had been reared and treated similarly, and two of the three HP sheep used previously. The two HP sheep and two of the LP animals were dosed orally with a single dose of 1500 third-stage infective $O$. columbianum juveniles 14 days after the start of the pre-infection observations. At the same time, for 5 consecutive days, the other two LP sheep were dosed with 300 juveniles daily, giving a total dose again of 1500 parasites. Ten days after the initial infections were administered, the stained particles were fed to the sheep and observations re-commenced.

\section{RESULTS}

\section{Pre-infection}

The rate of excretion of the stained particles by the LP sheep was slower than that by the HP sheep (Fig. I), the mean retention time of the former animals being significantly longer than that of the latter $(P<0.05)$ (Table 2). Analysis of the results for

Table 2. Live weight, feed intake and mean retention times of food particles for groups of sheep before and after infection with Oesophagostomum columbianum

\begin{tabular}{|c|c|c|c|c|c|c|c|}
\hline \multirow[b]{2}{*}{ Group } & \multirow{2}{*}{\multicolumn{3}{|c|}{ Sheep }} & \multirow{2}{*}{$\begin{array}{l}\text { Mean live weight } \\
\text { over sampling } \\
\text { period } \\
(\mathrm{kg})\end{array}$} & \multicolumn{2}{|c|}{$\begin{array}{l}\text { Mean feed intake } \\
\text { per day over } \\
\text { sampling period }\end{array}$} & \multirow{2}{*}{$\begin{array}{l}\text { Mean reten- } \\
\text { tion time } \\
\text { (h) }\end{array}$} \\
\hline & & & & & (g) & $\left(\mathrm{g} / \mathrm{kg} \mathrm{wt^{0.75 }}\right)$ & \\
\hline HP, not infected & A & B & $\mathrm{C}$ & $32 \cdot 6$ & 847 & $62 \cdot 2$ & 50.9 \\
\hline LP, not infected & $\mathrm{D}$ & $\mathbf{E}$ & $\mathbf{F}$ & $27 \cdot 9$ & 662 & $54 \%$ & $55^{\circ} \circ$ \\
\hline $\mathrm{HP}$, infected & $\mathrm{A}$ & $\mathbf{B}$ & & $35 \cdot 7$ & 820 & $56 \cdot 3$ & 60.8 \\
\hline LP, infected & $\mathrm{E}$ & $\mathrm{F}$ & & $23 \cdot 1$ & 442 & $42 \cdot 4$ & 70.5 \\
\hline LP, infected gradually & $\bar{D}$ & $\mathrm{G}$ & & $23 \cdot 2$ & 319 & 30.7 & $94: 7$ \\
\hline Pooled variance & & & & $8 \cdot 47$ & $\mathrm{NC}^{*}$ & $20 \cdot 35$ & $3 \cdot 8 I$ \\
\hline
\end{tabular}

HP, high-plane diet; LP low-plane diet (see Table r). * Non-compatible pooled variance.

all six animals revealed a highly significant negative correlation between the mean retention time and feed intake when expressed as $\mathrm{g} / \mathrm{kg}$ live weight ${ }^{0.75}(r=-0.98$; $P<$ O०OI).

\section{Post-infection}

The rates of excretion of the stained particles by the three groups of infected sheep are illustrated in Fig. 2. The rate was fastest for the HP group and slowest for the gradually infected LP group with the singly dosed LP group intermediate. Infection of the LP sheep resulted in significant depressions in feed intake $/ \mathrm{kg}$ live weight ${ }^{0.75}$ $(P<0.05$ for the single-infection group and $P<0.0$ I for the gradually infected group) and significant increases in mean retention time $(P<0.01$ for the single- 


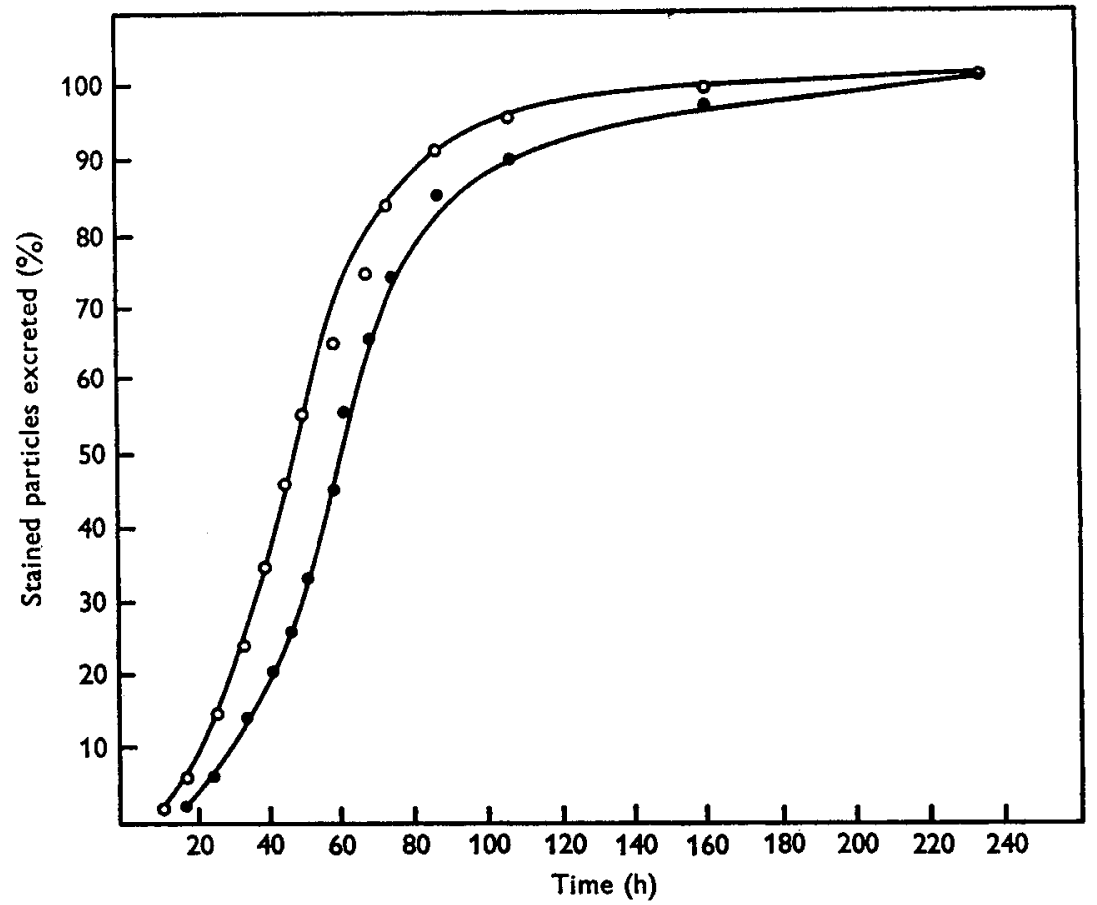

Fig. I. Rate of excretion of stained food particles by sheep maintained on a low or a high (O-O) plane of nutrition.

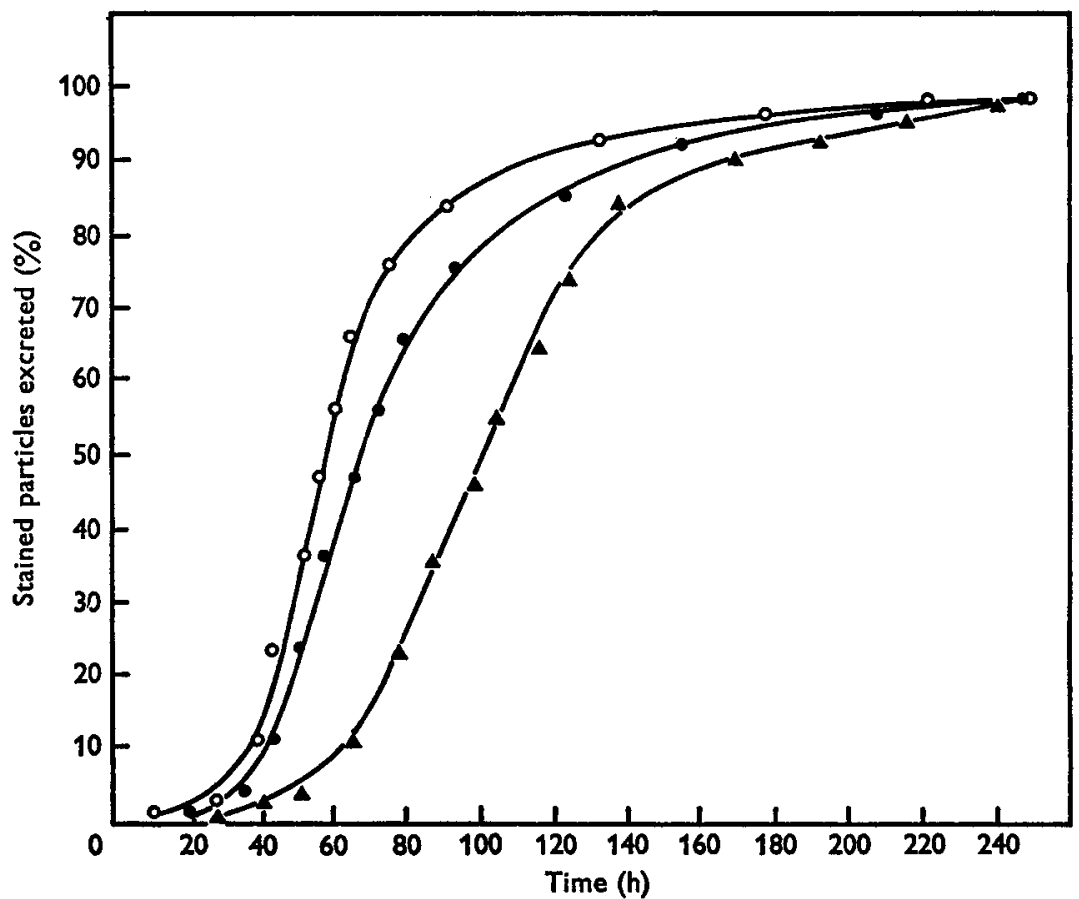

Fig. 2. Rate of excretion of stained food particles by sheep maintained on a low ( $\mathbf{A}-\mathbf{\Delta}$ ) or on a high $(\mathrm{O}-\mathrm{O}$ ) plane of nutrition and given orally for 5 days a daily dose of Oesophagostomum columbianum, and of sheep maintained on a low plane of nutrition and given orally the same amount of $O$. columbianum in a single dose (-) 
infection group and $P<0.001$ for the gradually infected group). The mean retention time of the HP group was also significantly increased following infection $(P<0.01)$, although food intake was not statistically significantly depressed. Nevertheless, a marked overall trend was evident in the experiment between mean retention time and feed intake expressed as $\mathrm{g} / \mathrm{kg}$ live-weight ${ }^{0.75}$, the latter decreasing as the former increased.

\section{DISCUSSION}

The rate of flow of food residues through the alimentary tract of helminth-free sheep was faster in those animals maintained on a ration of chopped lucerne hay than in those which received a mixture of chopped wheaten straw and molasses. This result is similar to that noted by Freer \& Campling ( 1963 ) who recorded an inverse relationship between the fibre content of the ration of cattle and its rate of disappearance from the reticulo-rumen.

The results of the present trials indicated that the rate of flow of food residues before infection was directly correlated with the amount of feed consumed by the sheep and this is in agreement with the results of Blaxter et al. (1956), Blaxter, Wainman \& Wilson (1961) and Coombe \& Tribe (1963). Similar results have been recorded for cattle (Balch, 1950; Mäkelä, 1956) and goats (Castle, 1956). No correlation was apparent between the mean length of time that ingesta was retained in the alimentary tract (mean retention time) and the metabolic weight of the animals. This result also confirms that of Coombe \& Tribe ( 1963$)$.

Infection of the sheep with 1500 infective $O$. columbianum juveniles was found to increase the mean retention time in all of the animals so affected. The extent of these increases was related both to the diet of the animal and the manner in which it had been infected. Thus the retention time of the LP animals was increased by a greater proportion than that of the HP ones. Furthermore, the administration of small graded infective doses to the LP animals resulted in greater increases in retention times than the administration of a single large dose.

The results suggest that the increase in mean retention time following infection was associated with the decreased feed intake of the animals at that time. The amount of food which ruminants consume is a function of the physical capacity of the reticulorumen (Blaxter et al. 1 961) and the rate at which the digesta leaves the organ (Campling, Freer \& Balch, 1962). The presence of $O$. columbianum juveniles in the intestine could affect peristaltic propulsion and in so doing delay the movement of ingesta from the reticulo-rumen which in turn would suppress the appetite. Gordon (1950) has suggested that the nodules which are associated with infections of $O$. columbianum in sheep interfere markedly with bowel movements, and Platt ( 1963$)$ has observed the interference of normal rhythmic contractions of the small intestines of rats infected with Nippostrongylus brasiliensis. Such observations could be associated with the suggestion by Rogers (1955) that the metabolic end-products of parasitic nematodes may be toxic to the host and cause partial paralysis of the intestine.

On the other hand, it could be argued that the depression in appetite which accompanies $O$. columbianum infections is an effect of the pain caused by the activities of the 
juvenile nematodes in the gut. In this case the increased mean retention times associated with infection could result indirectly from the decreased intake of food. It is suggested that a combination of both phenomena is involved.

An association is evident between the rate of flow of food residues and changes associated with infection, as reported in the present experiments, and the changes, similarly associated, in the efficiency of utilization of ingested nutrients (Bawden, 1969a). Thus the faster the flow the greater the efficiency of utilization and this result confirms that of Blaxter et al. (1956).

The changes in the rates of passage of food residues through the alimentary tract of sheep caused by infection with $O$. columbianum, besides possibly impairing certain metabolic processes, may influence the survival of the nematodes in the host. The number of such nematodes which survived in the various nutritional groups of sheep has been recorded (Bawden, $\mathrm{x} 969 \mathrm{~b}$ ) and it is interesting to note in this connexion that those sheep which harboured the greatest number of nematodes at $5^{6}$ days after infection had the longest mean retention times at ro days after infection. Similarly, the animals with the shortest retention times at yo days harboured the smallest number of nematodes at 56 days after infection.

An association between the rate of flow of ingesta through the alimentary tract of rats and the establishment of the cestode Hymenolepis fraterna $(=H$. nana var. fraterna) and the nematodes Ascaris lumbricoides and Trichinella spiralis has been established by Larsh (1947, 1950) and Larsh \& Hendricks (1949). These workers were able to increase the number of helminths becoming established by slowing the intestinal emptying time.

This work was supported by a grant from the Australian Wool Board. The interest and advice of Professor J. F. A. Sprent is gratefully acknowledged. The author is indebted to Dr V. Bofinger and Mr E. Hannah for their assistance with the statistical treatment of the results and to Mr G. Orr for his competent technical assistance.

\section{REFERENCES}

Association of Official Agricultural Chemists (1960). Official Methods of Analysis, 9th ed. Washington, D.C. Association of Official Agricultural Chemists.

Balch, C. C. (1950). Br. F. Nutr. 4, 36r.

Bawden, R. J. (1969a). Aust. F. agric. Res. 20, 589.

Bawden, R. J. (1969b). Aust. F. agric. Res. 20, I I 5 I.

Blaxter, K. L., Graham, N. McC. \& Wainman, F. W. (1956). Br. F. Nutr. ro, 69.

Blaxter, K. L., Wainman, F. W. \& Wilson, R. S. (196r). Anim. Prod. 3, 51.

Campling, R. C., Freer, M. \& Balch, C. C. (1962). Br. F. Nutr. r6, I 5 .

Castle, E. J. (1956). Br. Y. Nutr. 10, 15.

Coombe, J. B. \& Tribe, D. E. (1963). Aust. F. agric. Res. 14, 70.

Freer, M. \& Campling, R. C. (1963). Br. Y. Nutr. 17, 79.

Gordon, H. McL. (1950). Aust. vet. F. 26, 14.

Larsh, J. E. Jr (1947). F. Parasit. 33, 79.

Larsh, J. E. Jr (1950). Science, N.Y. III, 62.

Larsh, J. E. Jr \& Hendricks, J. R. (1949). F. Parasit. 35, Ior.

Mäkelä, A. (1956). Suom. Maataloust. Serv. Ұulk. 85, I.

Platt, B. S. (1963). Mimeographed Document. WHO/Helminth/61. Expert Committee on Helminthiases (Soil-transmitted Helminths). Rio de Janeiro, August 1963.

Rogers, W. P. (1 955). Expl Parasitol. 4, 21.

\section{Printed in Great Britain}

